\title{
Toll-like receptor (TLR) expression and TLR-mediated interleukin-8 production by human submandibular gland epithelial cells
}

\author{
KOUJI OHTA, YOKO ISHIDA, AKIKO FUKUI, KUNIKO MIZUTA, \\ HIROMI NISHI, MASAAKI TAKECHI and NOBUYUKI KAMATA \\ Department of Oral and Maxillofacial Surgery, Graduate School of Biomedical and Health Sciences, \\ Hiroshima University, Hiroshima 734-8553, Japan
}

Received October 22, 2013; Accepted May 23, 2014

DOI: $10.3892 / \mathrm{mmr} .2014 .2507$

\begin{abstract}
Toll-like receptor (TLR) family members are pattern recognition receptors that are essential in the activation of innate and adaptive immune responses. Submandibular gland epithelial cells (SMGCs) may recognize microbial components through TLRs and be involved in the development of inflammatory reactions in the submandibular glands. Therefore, the functional expression of TLRs in SMGCs was investigated in the present study. The mRNA expression of TLRs in SMGC and whole submandibular tissues was determined by RT-PCR. Subsequently, the effects of various TLR agonists and tumor necrosis factor alpha (TNF- $\alpha$ ) on IL-8 production were examined using an ELISA. SMGCs, as well as whole submandibular tissues, expressed TLR1-10 mRNA. Furthermore, interleukin (IL)-8 production in SMGCs was increased by Pam3CSK4 (TLR1/2 agonist), poly I:C (TLR3 agonist), E. coli lipopolysaccharide (LPS; TLR4 agonist), flagellin (TLR5 agonist) and macrophage-activating lipopeptide (MALP)-2 (TLR2/6 agonist) treatments in a dose-dependent manner, whereas administration of either imiquimod (TLR7 agonist) or CpG-oligodeoxynucletide (TLR9 agonist) exerted no evident effect. Pam3CSK4, poly I:C, LPS, flagellin and MALP-2 also enhanced TNF- $\alpha$-induced IL-8 production in SMGCs. These findings suggest that innate immune responses against microbial components result in the development of TNF- $\alpha$-mediated autoimmune inflammatory disease in the submandibular glands.
\end{abstract}

Correspondence to: Dr Kouji Ohta, Department of Oral and Maxillofacial Surgery, Graduate School of Biomedical and Health Sciences, Hiroshima University, 1-2-3 Kasumi, Hiroshima 734-8553, Japan

E-mail: otkouji@hiroshima-u.ac.jp

Key words: submandibular gland epithelial cells, Toll-like receptor, interleukin- 8 , tumor necrosis factor- $\alpha$

\section{Introduction}

Host recognition of microbes is primarily mediated by Toll-like receptors (TLRs), which bind highly conserved pathogen-associated molecular patterns (PAMPs) typically shared by groups of microorganisms (1). Each member of the TLR family has been shown to recognize the PAMPs of bacteria, fungi and/or viruses $(2,3)$. TLR2 forms a heterodimer with either TLR1 or TLR6 to recognize bacterial tri- or diacyl-lipopeptides, while TLR3, 4 and 5 recognize double-stranded RNA, Gram-negative bacterial lipopolysaccharide (LPS) and bacterial flagellin, respectively. TLR7 and 8 recognize single-stranded RNA found in certain viruses, and TLR9 recognizes the hypomethylated CpG motifs of bacterial DNA. However, the PAMP recognized by TLR10 is unknown. Following ligation, TLR signaling results in priming of the adaptive immune system and initiation of inflammatory responses via the induction of pro-inflammatory cytokines and chemokines $(4,5)$. In addition, activation of TLRs appears to be involved in the pathogenesis of autoimmune disorders, as suggested by the induction or promotion of organ-specific autoimmune lesions observed in various experimental animal models (6-8).

The expression of various types of TLR molecules in several types of epithelial tissue, including oral, gastrointestinal, bronchial and urinary epithelia, supports the hypothesis that the epithelium serves a critical function as the defensive front line of the innate immune system (9-11). TLRs in salivary glands have also been shown to be associated with the promotion of inflammatory reactions in autoimmune diseases, such as Sjögren's syndrome (SS) and autoimmune sialoadinitis $(12,13)$. Therefore, submandibular gland epithelial cells (SMGCs) appear to be actively involved in the induction of tissue reactions against pathogens in inflammatory autoimmune diseases via TLRs in the salivary glands.

Cytokines have a central role in the regulation of immunity, but dysregulation of the cytokine network can contribute to autoimmune disorders in salivary glands (14). Tumor necrosis factor (TNF)- $\alpha$ and interleukin (IL)- 8 have been identified in functionally and structurally damaged areas of salivary glands, and have also been implicated in disease pathogenesis (15-17). 
Previously, various TLR agonists were shown to cause secretion of pro-inflammatory cytokines, such as IL-8, and augment TNF- $\alpha$-mediated inflammatory responses in oral keratinocytes and fibroblasts (18). These findings may suggest that inflammatory cytokines in SMGCs are induced by PAMPs and implicated in the development of TNF- $\alpha$-mediated inflammatory diseases of the salivary glands. In the present study, IL-8 production from SMGCs in response to various TLR agonists was examined. The combined effect of TLR agonists and TNF- $\alpha$ on the production of IL- 8 was also investigated.

\section{Materials and methods}

Cell lines. Primary cultures of human SMGCs obtained from patient specimens extracted during submandibular gland extraction surgery for sialolithiasis (Hiroshima University Hospital, Hiroshima, Japan) were prepared. Informed consent from all participants was obtained according to a protocol approved by the Ethics Committee of Hiroshima University, Japan. SMGCs were established using an explant outgrowth technique, as previously described (19). At 70-80\% confluence, each primary culture was trypsinized, then serially transferred to culture vessels in serum-free keratinocyte basal medium (KBM; Lonza, Walkersville, MD, USA) as described previously (19). For molecular analyses, normal submandibular gland tissues at the time of submandibular gland extraction surgery, subsequent to obtaining informed consent and approval from the Institutional Review Board at Hiroshima University Hospital, were collected and frozen immediately in liquid nitrogen, and stored at $-80^{\circ} \mathrm{C}$.

$R N A$ extraction and reverse transcription-polymerase chain reaction $(R T-P C R)$. Total RNA was prepared from SMGCs and whole submandibular gland tissues using an RNeasy total RNA isolation kit (Qiagen, Hilden, Germany). Single-stranded cDNA for a PCR template was synthesized from a First Strand cDNASynthesis kit(AmershamBiosciences, Uppsala,Sweden). Target cDNA was amplified by PCR with an RT-PCR High Plus system (Toyobo, Osaka, Japan), using the following specific primers: Sense: 5'-AATTGATCTGGGTGGTGAGC-3' and antisense: 5'-GCCAACGGTAGCTTGACATT-3' for amylase; sense: 5'-CCGTGTCCAAGAAAACCAGA-3' and antisense: 5'-CAGCTGTGTGATGGGAGCTA-3' for chromogranin B; sense: 5'-GCCAAGCAGACGAGGACTAC-3' and antisense: 5'-GGAGCACACCATCACACATC-3' for kallikrein I; and sense: 5'-GGTCAGGCTCTCTTCACTGG-3' and antisense: 5'-CCCTTCCCCCAGTTGAGTAT-3' for claudin I. The PCR conditions were as follows: One cycle at $95^{\circ} \mathrm{C}$ for $15 \mathrm{~min}$, four cycles of $95^{\circ} \mathrm{C}$ for $2 \mathrm{~min}, 59^{\circ} \mathrm{C}$ for $30 \mathrm{sec}$ and $72^{\circ} \mathrm{C}$ for $1 \mathrm{~min}$ and one cycle at $72^{\circ} \mathrm{C}$ for $7 \mathrm{~min}$. The products were analyzed on $2 \%$ agarose gels. $\beta$-actin was included as an internal control.

TLR agonists. The TLR agonists used in this study were purchased from Imgenex Corporation (San Diego, CA, USA) and included Pam3CSK4, a synthetic bacterial lipopeptide (TLR1/2 agonist); poly I:C, a synthetic virus double-stranded RNA (TLR3 agonist); E. coli LPS, a synthetic cell wall component of gram-negative bacteria (TLR4 agonist); flagellin from Salmonella Typhimurium, a synthetic bacterial flagellin (TLR5 agonist); macrophage-activating lipopeptide (MALP-2), a synthetic Mycoplasma lipopeptide (TLR2/6
A

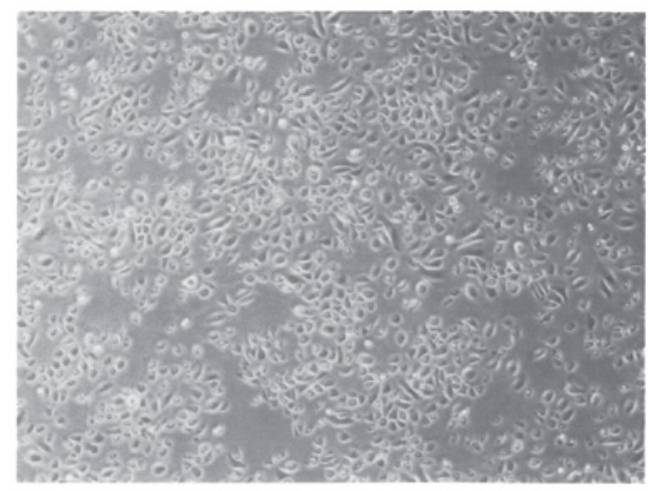

B

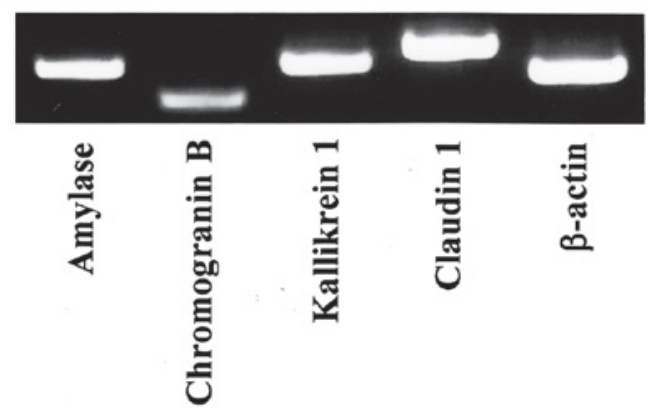

Figure 1. Morphology and expression levels of salivary gland-associated genes in SMGCs. (A) Morphological features of SMGCs cultured in serum-free keratinocyte basal medium. SMGCs were observed to have a cobblestone-like epithelial appearance (original magnification, x100). (B) mRNA expression levels of salivary gland-associated genes in SMGCs. Total RNA was isolated from confluent SMGCs, subsequent to which reverse transcription-polymerase chain reaction was performed for amylase, chromogranin B, kallikrein 1 , claudin 1 and $\beta$-actin. SMGCs, submandibular gland epithelial cells.

agonist); imiquimod (R-837), a synthetic molecule of the Imidazoquinoline family (TLR7 agonist); synthetic oligodeoxynucleotide (ODN) containing CpG motifs; and a synthetic bacterial DNA (TLR9 agonist).

Quantification of IL-8 protein. SMGCs were seeded into 96-well cell culture plates in KBM. To determine the maximal effective TLR agonist concentration with regard to activating capacity, IL-8 production was assessed following stimulation with the following agonists at various doses: $100 \mathrm{ng} / \mathrm{ml}-5 \mu \mathrm{g} / \mathrm{ml}$ Pam3CSK4, $100 \mathrm{ng} / \mathrm{ml}-5 \mu \mathrm{g} / \mathrm{ml}$ poly I:C, $1-20 \mu \mathrm{g} / \mathrm{ml}$ LPS, $10-500 \mathrm{ng} / \mathrm{ml}$ flagellin, $10-500 \mathrm{ng} / \mathrm{ml}$ MALP-2 and $0.1-10 \mu \mathrm{g} / \mathrm{ml}$ imiquimod. As determined by these results, in subsequent experiments, cells were exposed to $1 \mu \mathrm{g} / \mathrm{ml} \mathrm{Pam} 3 \mathrm{CSK} 4,1 \mu \mathrm{g} / \mathrm{ml}$ poly I:C, $10 \mu \mathrm{g} / \mathrm{ml}$ E. coli LPS, $100 \mathrm{ng} / \mathrm{ml}$ flagellin, $500 \mathrm{ng} / \mathrm{ml}$ MALP-2, $10 \mu \mathrm{g} / \mathrm{ml}$ imiquimod, $10 \mu \mathrm{g} / \mathrm{ml} \mathrm{CpG-ODN}$ or GpC (negative ODN) as a negative control to $\mathrm{CpG}-\mathrm{ODN}$. To half these cells, $10 \mathrm{ng} / \mathrm{ml} \mathrm{TNF-} \alpha$ was added, and the cells were incubated for $48 \mathrm{~h}$.

The collected medium samples were centrifuged and the supernatant fluids stored at $-80^{\circ} \mathrm{C}$ prior to performing assays. The IL-8 protein level in the medium was determined using an ELISA kit (R\&D Systems, Minneapolis, MN, USA), according to the manufacturer's instructions.

Statistical analysis. Data were analyzed using Student's t-test or one-way analysis of variance using the Bonferroni or Dunn method and the results are presented as the mean \pm standard deviation. 
A

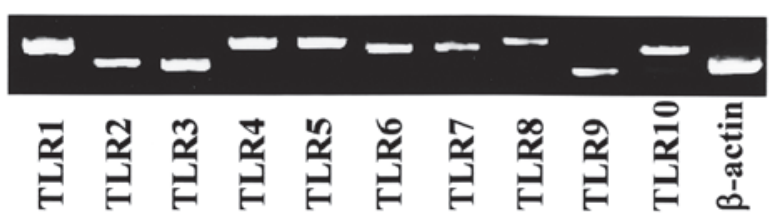

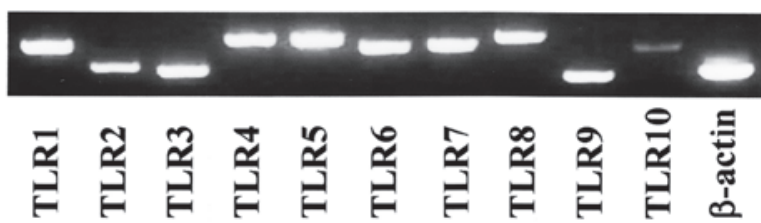

Figure 2. mRNA expression levels of TLR1-10 in SMGCs and whole submandibular tissue specimens. (A) TLR mRNA expression levels in SMGCs. (B) TLR mRNA expression levels in whole submandibular tissue specimens. Total RNA was isolated from SMGCs in a confluent condition and whole submandibular gland specimens, subequent to which reverse transcription-polymerase chain reaction assays were performed for TLR1-10 and $\beta$-actin. TLR, Toll-like receptor; SMGCs, submandibular gland epithelial cells.
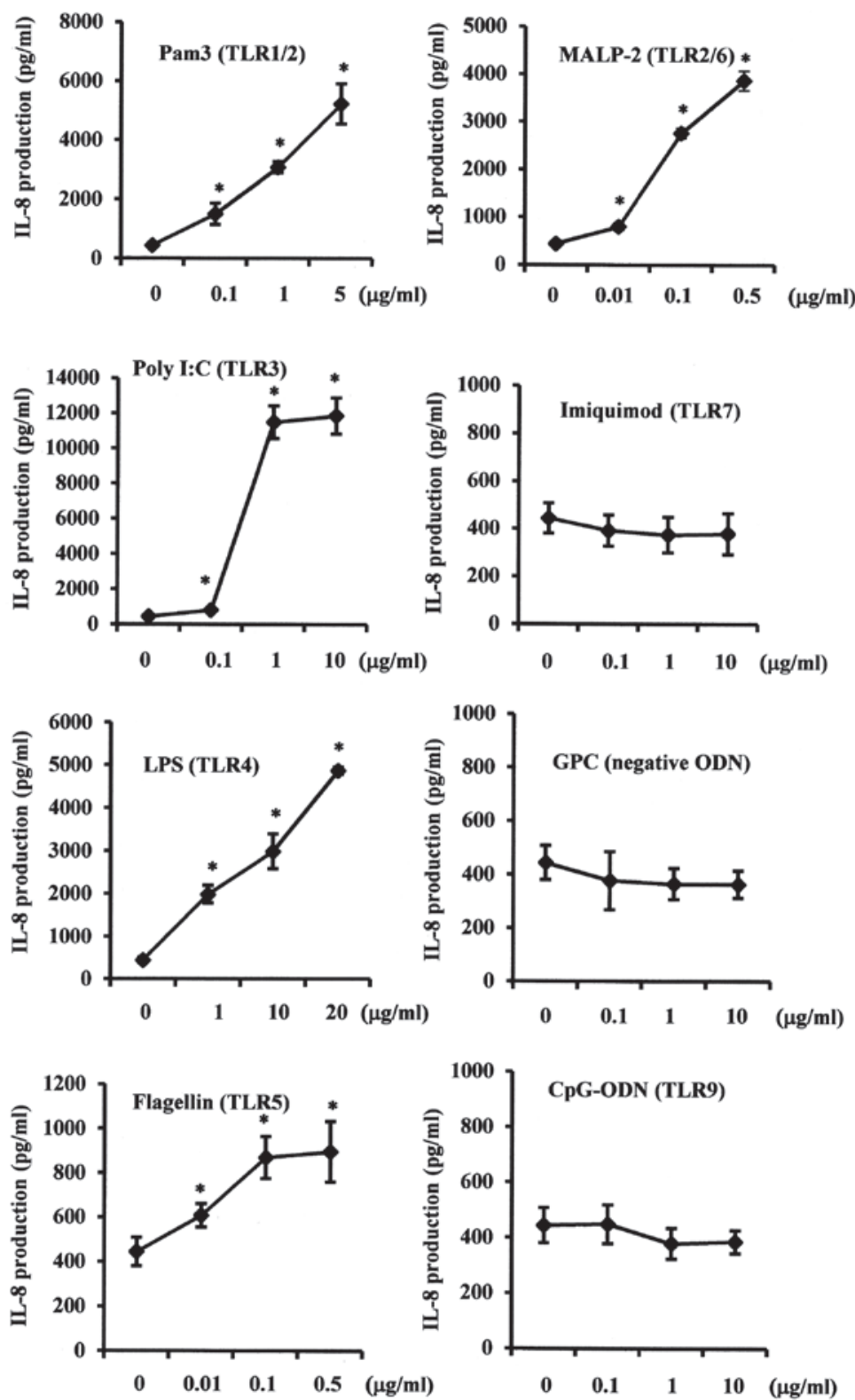

Figure 3. Effects of various TLR agonists on IL-8 protein expression levels in SMGCs. Cells were cultured and stimulated with various TLR1-9 agonist concentrations for $48 \mathrm{~h}$. Data are shown as the mean \pm standard deviation of three independent experiments. "P $<0.05$ compared with non-treated cells (Dunnett's test). TLR, Toll-like receptor; SMGCs, submandibular gland epithelial cells; MALP, macrophage-activating lipopeptide; LPS, lipopolysaccharide; ODN, oligodeoxynucleotide; IL, interleukin.

\section{Results}

Establishment of SMGCs. SMGCs were established using an explant outgrowth method (19). The epithelial origin of cultured SMGCs was verified by morphology and uniformity (Fig. 1A), and SMGCs were also shown to constitutively express salivary gland-associated genes, such as amylase, chromogranin B, kallikrein 1 and claudin 1 (Fig. 1B) (19, 20). 
A

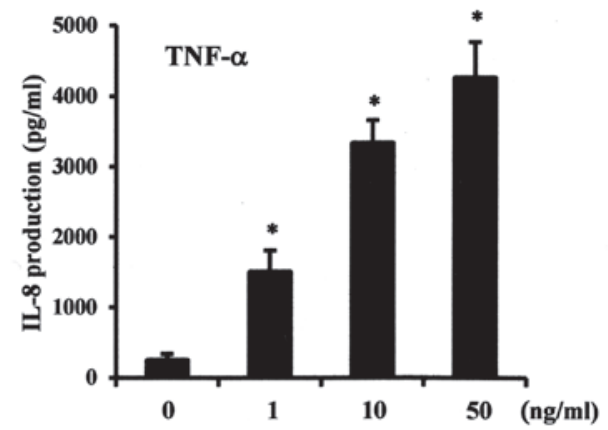

B

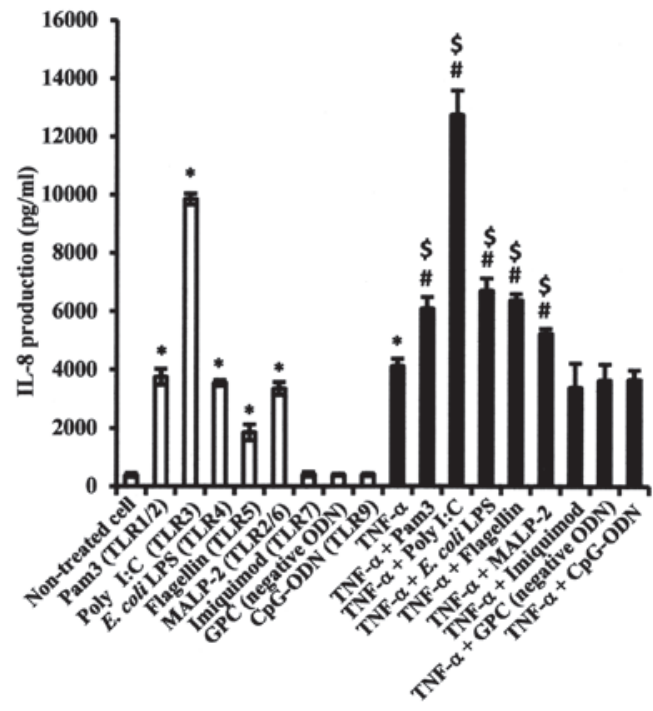

Figure 4. Effects of various TLR agonists on TNF- $\alpha$-induced IL-8 protein expression levels in SMGCs. (A) SMGCs were stimulated with various concentrations of TNF- $\alpha$. (B) SMGCs were stimulated with TLR1-9 agonists and TNF- $\alpha$, administered alone or in combination. Cells were cultured, then exposed to $1 \mu \mathrm{g} / \mathrm{ml}$ Pam3CSK4, $1 \mu \mathrm{g} / \mathrm{ml}$ poly I:C, $10 \mu \mathrm{g} / \mathrm{ml} E$. coli $\mathrm{LPS}$, $100 \mathrm{ng} / \mathrm{ml}$ flagellin, $500 \mathrm{ng} / \mathrm{ml}$ MALP-2, $10 \mu \mathrm{g} / \mathrm{ml}$ imiquimod, $10 \mu \mathrm{g} / \mathrm{ml}$ $\mathrm{CpG}-\mathrm{ODN}$ or $\mathrm{GpC}$ (negative ODN) as a negative control to $\mathrm{CpG}-\mathrm{ODN}$. An additional $10 \mathrm{ng} / \mathrm{ml}$ TNF- $\alpha$ was added to half the cells in each treatment group, and the cells were incubated for $48 \mathrm{~h}$, subsequent to which the levels of IL-8 in the culture supernatants were measured by ELISA. Data are shown as the mean \pm standard deviation of three independent experiments. ${ }^{*} \mathrm{P}<0.05$ compared with non-treated cells (Student's t-test). ${ }^{\prime \prime} \mathrm{P}<0.05$ compared with TNF- $\alpha$ alone (Student's t-test). ${ }^{\$} \mathrm{P}<0.05$ compared with TLR agonists alone (Student's t-test). TLR, Toll-like receptor; SMGCs, submandibular gland epithelial cells; TNF, tumor necrosis factor; LPS, lipopolysaccharide; MALP, macrophage-activating lipopeptide; ODN, oligodeoxynucleotide.

TLR mRNA expression in SMGCs and whole submandibular gland tissue specimens. As shown in Fig. 2, SMGCs and whole submandibular gland tissue samples expressed TLR1-10 mRNA.

Effects of TLR agonists on IL-8 expression levels in SMGCs. Since functional TLRs induce biological responses, the effects of various TLR agonists on IL-8 expression levels in SMGCs were examined.Pam3CSK4 (TLR1/2), poly I:C (TLR3), E. coli LPS (TLR4), flagellin (TLR5) and MALP-2 (TLR2/6) each significantly increased IL-8 production in a dose-dependent manner $(\mathrm{P}<0.05)$, whereas no statistically significant effect was exerted by imiquimod (TLR7) or CpG-ODN (TLR9) (Fig. 3).
Effects of PAMPs on TNF- $\alpha$-induced IL- 8 production in $S M G C s$. The effects of combinations of TLR agonists and TNF- $\alpha$ on IL-8 expression levels were also examined. TNF- $\alpha$ significantly increased IL-8 production in SMGCs in a dose-dependent manner ( $\mathrm{P}<0.05$; Fig. 4A), while Pam3CSK4, poly I:C, LPS, flagellin and MALP-2 significantly enhanced TNF- $\alpha$-induced IL- 8 production in SMGCs, when compared with either the respective TLR agonist or TNF- $\alpha$ administered alone ( $\mathrm{P}<0.05$; Fig. 4B).

\section{Discussion}

TLRs are essential in the activation of innate and adaptive immune responses in salivary gland inflammation (12). mRNA expression of various TLR family members has been reported in whole human salivary gland tissues containing heterogeneous cell populations $(21,22)$. In addition, certain studies have shown that salivary gland epithelial cells (SGECs) constitutively express particular TLRs. SGECs derived from SS patients and non-neoplastic SGECs in labial minor salivary glands were observed to exhibit marked constitutive expression of TLR1, 2, 3 and 4 mRNA (12). Furthermore, TLR1-5 were found to be expressed in salivary gland adenocarcinoma cells (23). SMGCs derived from minor salivary glands were determined to express TLR2, 3 and 7, but not TLR9 (24). In another study, TLR7 and TLR9 were detected in ductal epithelial cells in parotid gland biopsy specimens obtained from SS patients and control subjects (25). In the present study, SMGCs and whole submandibular gland tissue specimens were shown to constitutively express TLR1-10 mRNA. Furthermore, imiquimod (TLR7 agonist) and CPG-ODN (TLR9 agonist) were found to exert no effect on IL-8 induction in SMGCs. It is unknown whether TLR7 and TLR9 in SMGCs function to recognise PAMPs. Therefore, the roles of TLR7 and TLR9 in SGECs may remain controversial.

Stimulation of TLR signaling results in the production and expression of inflammatory mediators, including IL-6, IL-8 and TNF- $\alpha$ (1-3), which are critically involved in the disease processes of human inflammatory disorders. Local TLR expression has been reported in SS and autoimmune sialadenitis $(12,13)$. Peptidoglycan (PGN; TLR2 agonist), poly I:C (TLR3 agonist) and LPS (TLR4 agonist) were found to increase CD54 and IL-6 expression levels in labial salivary gland cells (26). Furthermore, flagellin (TLR5 agonist) led to production of IL-6 and IL-8 in salivary gland adenocarcinoma samples, although Pam3 (TLR1/2 agonist) and LPS (TLR4 agonist) did not exert an effect on cytokine production (23). Poly I:C (TLR3 agonist) treatment was shown to increase interferon and inflammatory cytokine expression levels in mice salivary gland cells (27). In the present study, IL-8 production from SMGCs was found to be induced by TLR1/2, $3,4,5$ and 2/6 agonists, of which poly I:C, a TLR3 agonist, markedly induced the production of IL-8. Thus, the presence of TLR3 suggests a role of the submandibular gland cells in the antiviral response.

Pro-inflammatory cytokines, such as TNF- $\alpha$, have been reported to be associated with salivary gland loss of function and destruction. SGECs in SS biopsy samples were observed to produce TNF- $\alpha$ mRNA in greater quantities than SGECs from individuals with histologically normal minor salivary 
glands (15). Also, TNF- $\alpha$ secreted by infiltrating lymphocytes induced ductal Fas expression and ductal apoptosis in sialoadenitis associated with SS (28). The present study demonstrated that the addition of TLR1/2,3,4,5 and 2/6 agonists resulted in an increase in TNF- $\alpha$-induced IL- 8 production in SMGCs. IL- 8 is important for neutrophil activation and recruitment, and undue downregulation of this function may compromise the antimicrobial defense. However, an unduly vigorous or sustained IL-8 response may result in chronic inflammatory tissue destruction (29). Certain investigators have reported that increases in various TLR expression levels were identified in SGECs in the minor salivary gland of patients with SS, as compared with control subjects $(12,26)$. Therefore, pro-inflammatory cytokines, including IL-8, induced by various PAMPs via TLRs may be implicated in the development of TNF- $\alpha$-mediated autoimmune inflammatory disease of the submandibular glands.

With the majority of TLR agonists, the signaling pathways are mainly mediated by the activation of $\mathrm{NF}-\kappa \mathrm{B}$ and mitogen-activated protein kinase (MAPK), although cell-surface TLR4 and intracellular TLRs (TLR3, 7, 8 and 9) also activate cells via interferon regulatory factor (IRF)-3 and/or IRF-7 (30). It has been reported that PGN, poly (I:C) and LPS also induced activation of the NF- $\kappa$ B and p38 MAPK pathways in SGECs in the minor salivary gland $(26,31)$, while $\mathrm{TNF}-\alpha$ activates nuclear factor- $\kappa \mathrm{B}$, which is involved in inflammatory cytokine signaling pathways, such as IL-8 and IL-6 via MAPK $(32,33)$. In the present study, TNF- $\alpha$-induced IL-8 production was enhanced by almost all TLR ligands, which may be explained by cooperative signaling among TNF- $\alpha$ and TLR agonists to induce IL-8 in SMGCs.

In conclusion, the results of the present study demonstrated that SMGCs expressed TLR1-10 mRNA, that IL-8 production from SMGCs was induced by treatment with various TLR agonists and that the TLR agonists regulated TNF- $\alpha$-induced IL-8 production. This suggests that innate immune responses against microbial components result in the development of TNF- $\alpha$-mediated autoimmune inflammatory disease in the submandibular glands.

\section{Acknowledgements}

This study was supported by a Grant-in-Aid of scientific research from the Japan Society for Young Scientists (B) from the Ministry of Education, Culture, Sports, Science and Technology of Japan (grant no. 21109871).

\section{References}

1. Takeda K, Kaisho T and Akira S: Toll-like receptors. Annu Rev Immunol 21: 335-376, 2003.

2. Midwood KS, Piccinini AM and Sacre S: Targeting Toll-like receptors in autoimmunity. Curr Drug Targets 10: 1139-1155, 2009.

3. Kumar H, Kawai T and Akira S: Toll-like receptors and innate immunity. Biochem Biophys Res Commun 388: 621-625, 2009

4. Han DC, Huang GT, Lin LM, et al: Expression of MHC Class II, CD70, CD80, CD86 and pro-inflammatory cytokines is differentially regulated in oral epithelial cells following bacterial challenge. Oral Microbiol Immunol 18: 350-358, 2003.

5. Kawai T, Takeuchi O, Fujita T, et al: Lipopolysaccharide stimulates the MyD88-independent pathway and results in activation of IFN-regulatory factor 3 and the expression of a subset of lipopolysaccharide-inducible genes. J Immunol 167: 5887-5894, 2001.
6. Anders HJ, Vielhauer V, Eis V, et al: Activation of toll-like receptor-9 induces progression of renal disease in MRL-Fas (lpr) mice. FASEB J 18: 534-536, 2004.

7. Kobayashi Y, Murakami H, Akbar SM, Matsui H and Onji M: A novel and effective approach of developing aggressive experimental autoimmune gastritis in neonatal thymectomized BALB/c mouse by polyinosinic:polycytidylic acid. Clin Exp Immunol 136: 423-431, 2004.

8. Qu WM, Miyazaki T, Terada M, et al: A novel autoimmune pancreatitis model in MRL mice treated with polyinosinic:polycytidylic acid. Clin Exp Immunol 129: 27-34, 2002.

9. Birchler T, Seibl R, Büchner K, et al: Human Toll-like receptor 2 mediates induction of the antimicrobial peptide human beta-defensin 2 in response to bacterial lipoprotein. Eur J Immunol 31: 3131-3137, 2001.

10. Böcker U, Yezerskyy O, Feick P, et al: Responsiveness of intestinal epithelial cell lines to lipopolysaccharide is correlated with Toll-like receptor 4 but not Toll-like receptor 2 or CD14 expression. Int J Colorectal Dis 18: 25-32, 2003.

11. Hertz CJ, Wu Q, Porter EM, et al: Activation of Toll-like receptor 2 on human tracheobronchial epithelial cells induces the antimicrobial peptide human beta defensin-2. J Immunol 171: 6820-6826, 2003.

12. Spachidou MP, Bourazopoulou E, Maratheftis CI, et al: Expression of functional Toll-like receptors by salivary gland epithelial cells: increased mRNA expression in cells derived from patients with primary Sjögren's syndrome. Clin Exp Immunol 147: 497-503, 2007.

13. Shimizu S, Kurashige Y, Nishimura M, et al: Involvement of toll-like receptors in autoimmune sialoadenitis of the non-obese diabetic mouse. J Oral Pathol Med 41: 517-523, 2012.

14. Roescher N, Tak PP and Illei GG: Cytokines in Sjögren's syndrome. Oral Dis 15: 519-526, 2009.

15. Fox RI, Kang HI, Ando D, Abrams J and Pisa E: Cytokine mRNA expression in salivary gland biopsies of Sjögren's syndrome. J Immunol 152: 5532-5539, 1994.

16. Cuello C, Palladinetti P, Tedla N, et al: Chemokine expression and leucocyte infiltration in Sjögren's syndrome. Br J Rheumatol 37: 779-783, 1998.

17. Pflugfelder SC, Jones D, Ji Z, Afonso A and Monroy D: Altered cytokine balance in the tear fluid and conjunctiva of patients with Sjögren's syndrome keratoconjunctivitis sicca. Curr Eye Res 19: 201-211, 1999.

18. Ohta K, Shigeishi H, Taki M, et al: Regulation of CXCL9/10/11 in human oral keratinocytes and fibroblasts. J Dent Res 87: 1160-1165, 2008.

19. Dimitriou ID, Kapsogeorgou EK, Abu-Helu RF, Moutsopoulos HM and Manoussakis MN: Establishment of a convenient system for the long-term culture and study of non-neoplastic human salivary gland epithelial cells. Eur J Oral Sci 110: 21-30, 2002.

20. Szlávik V, Szabó B, Vicsek T, et al: Differentiation of primary human submandibular gland cells cultured on basement membrane extract. Tissue Eng Part A 14: 1915-1926, 2008.

21. Nishimura $M$ and Naito $S$ : Tissue-specific mRNA expression profiles of human toll-like receptors and related genes. Biol Pharm Bull 28: 886-892, 2005.

22. Zarember KA and Godowski PJ: Tissue expression of human Toll-like receptors and differential regulation of Toll-like receptor mRNAs in leukocytes in response to microbes, their products, and cytokines. J Immunol 168: 554-561, 2002.

23. Park JH, Yoon HE, Kim DJ, et al: Toll-like receptor 5 activation promotes migration and invasion of salivary gland adenocarcinoma. J Oral Pathol Med 40: 187-193, 2011.

24. Ittah M, Miceli-Richard C, Gottenberg JE, et al: Viruses induce high expression of BAFF by salivary gland epithelial cells through TLR- and type-I IFN-dependent and -independent pathways. Eur J Immunol 38: 1058-1064, 2008.

25. Zheng L, Zhang Z, Yu C and Yang C: Expression of Toll-like receptors 7, 8, and 9 in primary Sjögren's syndrome. Oral Surg Oral Med Oral Pathol Oral Radiol Endod 109: 844-850, 2010.

26. Kawakami A, Nakashima K, Tamai M, et al: Toll-like receptor in salivary glands from patients with Sjögren's syndrome: functional analysis by human salivary gland cell line. J Rheumatol 34: 1019-1026, 2007.

27. Deshmukh US, Nandula SR, Thimmalapura PR, Scindia YM and Bagavant $\mathrm{H}$ : Activation of innate immune responses through Toll-like receptor 3 causes a rapid loss of salivary gland function. J Oral Pathol Med 38: 42-47, 2009. 
28. Matsumura R, Umemiya K, Goto T, et al: Interferon gamma and tumor necrosis factor alpha induce Fas expression and anti-Fas mediated apoptosis in a salivary ductal cell line. Clin Exp Rheumatol 18: 311-318, 2000.

29. Hajnická V, Kocáková P, Sláviková M, et al: Anti-interleukin-8 activity of tick salivary gland extracts. Parasite Immunol 23: 483-489, 2001

30. Akira S and Takeda K: Toll-like receptor signalling. Nat Rev Immunol 4: 499-511, 2004

31. Ittah M, Miceli-Richard C, Gottenberg JE, et al: B-cell-activating factor expressions in salivary epithelial cells after dsRNA virus infection depends on RNA-activated protein kinase activation. Eur J Immunol 39: 1271-1279, 2009.
32. Lisi S, Sisto M, Lofrumento DD and D'Amore M: Sjögren's syndrome autoantibodies provoke changes in gene expression profiles of inflammatory cytokines triggering a pathway involving TACE/NF-кB. Lab Invest 92: 615-624, 2012.

33. Li J, Kartha S, Iasvovskaia S, et al: Regulation of human airway epithelial cell IL-8 expression by MAP kinases. Am J Physiol Lung Cell Mol Physiol 283: L690-L699, 2002. 